\title{
Gravidez na adolescência: seus entornos, suas peculiaridades e o ponto de vista da adolescente
}

\author{
Adolfo Oscar Gigglberger Bareiro ${ }^{1}$ \\ Pontificia Universidade Católica do Paraná.nafg@uol.com.br
}

\section{RESUMO}

Este trabalho refere-se aos vários aspectos que envolvem a gravidez na adolescência, do ponto de vista delas. Tem como objetivo estudar o grau da informação das adolescentes, com relação ao período da gravidez, seu relacionamento com familiares como possível fator agravante, a menarca e iniciação sexual precoce, influenciando diretamente na gravidez, comparar os projetos de vida antes e após a gravidez e responder se a gravidez foi ou não desejada. Para isto, foi realizada uma pesquisa qualitativa, com uma amostragem de doze adolescentes grávidas que freqüentam a Unidade de Saúde Ferraria (Campo Largo). Os resultados mostram que as adolescentes não desejavam engravidar, porém, acabaram aceitando a idéia após tomarem conhecimento do seu estado gravídico. As adolescentes provêm de lares desestruturados, com laços familiares extremamente comprometidos, com iniciação sexual precoce, grau de escolaridade baixo e com projetos de vida cada vez mais difíceis de serem atingidos.

\section{INTRODUÇÃO}

Sabe-se que a adolescência compreende um período intermediário entre a infância e a fase adulta, com intensas mudanças biológicas, psicológicas e sexuais. Até 1986, a Organização Mundial da Saúde (OMS) considerou o período da adolescência a faixa etária entre 10 a 19 anos; no entanto, propôs como população jovem a faixa compreendida entre 10 a 24 anos, dividindo-a, para efeitos práticos de análise, em três subgrupos: 10 -14 anos, 15 - 19 anos e 20 -24 anos (OMS, 1986)*.

Muito se tem falado e estudado em relação à gravidez na adolescência, já que esta vem adquirindo proporções significativas. Tenta-se entender e justificar este fenômeno através dos muitos estudos, chegando-se a estimativa aproximada de $20-25 \%$ do total de mulheres gestantes no Brasil, apontando 1 adolescente em cada 5 mulheres grávidas (MINISTÉRIO DA SAÚDE, 1999).

Existe uma grande preocupação com as conseqüências que a maternidade precoce pode acarretar à saúde, educação, desenvolvimento econômico e social (LAO, 1997 E LESSER, 1999). O problema obstétrico em que a adolescente se constitui é em relação à primiparidade associado aos problemas social, econômico e educacional.

YAZLLE e COLS (2002) num estudo retrospectivo de 7134 partos em 4 anos, mostrou que $80 \%$ das adolescentes parturientes utilizaram o SUS (Sistema Único de Saúde) para internação, 85.5\% não possuíam nenhum tipo de emprego, sendo a complicação mais encontrada aquelas relacionadas ao trabalho de parto (12.4\%), as idades mais freqüentemente achadas foram 19 (29\%) e 18 anos (27\%) respectivamente. Existem controvérsias em relação à

\footnotetext{
* Neste estudo consideraremos a adolescência na faixa etária compreendida entre 11 a 20 anos.
} 
maior incidência de patologias clínico-obstétricas atribuídas à gestação na adolescência, sustentando a idéia de que a gravidez é fisicamente bem tolerada entre aquelas que recebem assistência pré-natal precoce e de forma regular (LAO, 1997). No entanto, há autores e estudos afirmando que as patologias encontradas nesta faixa etária não diferem significativamente, exceto algumas patologias isoladas, da população geral. No Hospital das Clínicas da FMUSP, de 1000 adolescentes do sexo feminino, no ano de 1993, a média de idade da primeira relação sexual foi de 16.4 anos.

Mc ANARNEY (1984) associa a precocidade da primeira relação com a mudança do comportamento sexual dos adolescentes como principais fatores da gravidez nesta faixa etária.

No que se refere à literatura sobre adolescência, CALAZANS (1997), na sua pesquisa realizada encontrou que o tema da sexualidade é o detentor do maior número de publicações, seguido pela gravidez na adolescência; sendo que nesta última a maioria dos trabalhos aborda os fatores de risco e complicações, prevenção do mesmo pela educação sexual, aspectos psicológicos, paternidade adolescente e relação com profissionais de saúde. Não se encontrou nenhum trabalho onde se tivesse uma visão mais ampla da gravidez na adolescência envolvendo o contorno familiar, social, psicológico e médico, se isto realmente representa um problema de saúde ou uma realização pessoal.

Vários são os fatores tidos como decisivos ou desencadeantes na iniciação sexual de um adolescente, tais como, menarca, estrutura familiar, escolaridade, pensamento mágico, acesso a métodos anticoncepcionais, deficiência dos serviços de saúde, manuseio do método contraceptivo e o projeto de vida do adolescente (MINISTÉRIO DA SAÚDE, 1999). Assim, quando analisamos os fatores envolvidos ou desencadeantes da gestação nesta faixa etária, percebemos a existência de uma complexa "rede multicausal" que torna os adolescentes vulneráveis a esta situação.

Estudos realizados pela Population Reference Bureau (1992) sobre gravidez na adolescência mostra que esta vem aumentando nas últimas décadas. No Brasil, as taxas de gravidez na adolescência variam de serviço, mas giram em torno de 20 - 25\% do total de gestantes, e isto sem levar em consideração os casos de aborto (MINISTÉRIO DA SAÚDE, 1999).

Na maioria das vezes, a iniciação sexual das adolescentes é feita com o namorado, sendo que a faixa etária na maioria das pesquisas gira em torno dos 15 a 17 anos como sendo o período mais comum. Em torno de 40 \% destas eram casadas ou vieram a casar-se durante a gestação, trazendo consigo outro tipo de problema: o filho socialmente indesejado, aumentando assim os índices de crianças abandonadas, mortalidade infantil e delinqüência infantil (LESSER, 1999).

Levantamos as seguintes hipóteses: as adolescentes não percebem a gravidez como um problema e sim como uma situação natural; há um forte fator de afirmação sobre a sua sexualidade e fecundidade com a gravidez; o sistema de saúde não atinge as expectativas; não fornece orientações necessárias, modo de encarar a situação e provimento de métodos anticoncepcionais esperado pelas pacientes; há grande prejuízo no projeto de vida.

A pesquisa realizada consiste num estudo descritivo, com um total de doze entrevistas realizadas com adolescentes grávidas, com idades compreendidas entre 11 e 20 anos. As pacientes freqüentam a Unidade de Saúde (U.S.) no bairro Ferraria do município de Campo Largo. Uma vez incluídas no estudo e após concordarem em fazer parte do mesmo, as pacientes foram entrevistadas através de um questionário, sendo que as entrevistas foram realizadas na Unidade de Saúde e no domicílio das pacientes, documentadas em fita-cassete. Todas as pacientes entre 11 a 19 anos que apresentaram teste positivo para gravidez ( $\beta$ HCG ou Teste 
Imunológico de Gravidez) ou que foram diagnosticados num período mais avançado da gestação pelo Pinard ou pelo Sonar - Doppler foram incluídas no estudo.

\section{PESQUISA QUANTITATIVA}

Foi desenvolvida uma pesquisa descritiva e exploratória junto às adolescentes grávidas, inscritas nos Programas de Humanização, Pré-Natal e Nascimento, do Município de Campo Largo, no segundo semestre de 2002. Foi utilizada uma amostra aleatória de 37 adolescentes grávidas entre 10 e 19 anos de idade, que fazem o pré-natal em uma das seis Unidades de Saúde com atendimento do Programa de Saúde da Família. Um questionário aplicado pelos médicos foi utilizado como instrumento de coleta de dados, tendo como variáveis de estudo: idade, escolaridade, situação conjugal, ocupação, relacionamento familiar, menarca, inicio da atividade sexual, paridade, fonte de informações sobre sexualidade, conhecimento de métodos contraceptivos, uso de métodos contraceptivos, planejamento da gravidez, projeto de vida e serviços que deverão ser implantados.

\section{GRÁFICO 1 - IDADE DE ADOLESCENTES GRÁVIDAS ENTREVISTADAS NAS UNIDADES DE SAÚDE DE CAMPO LARGO - 2002}

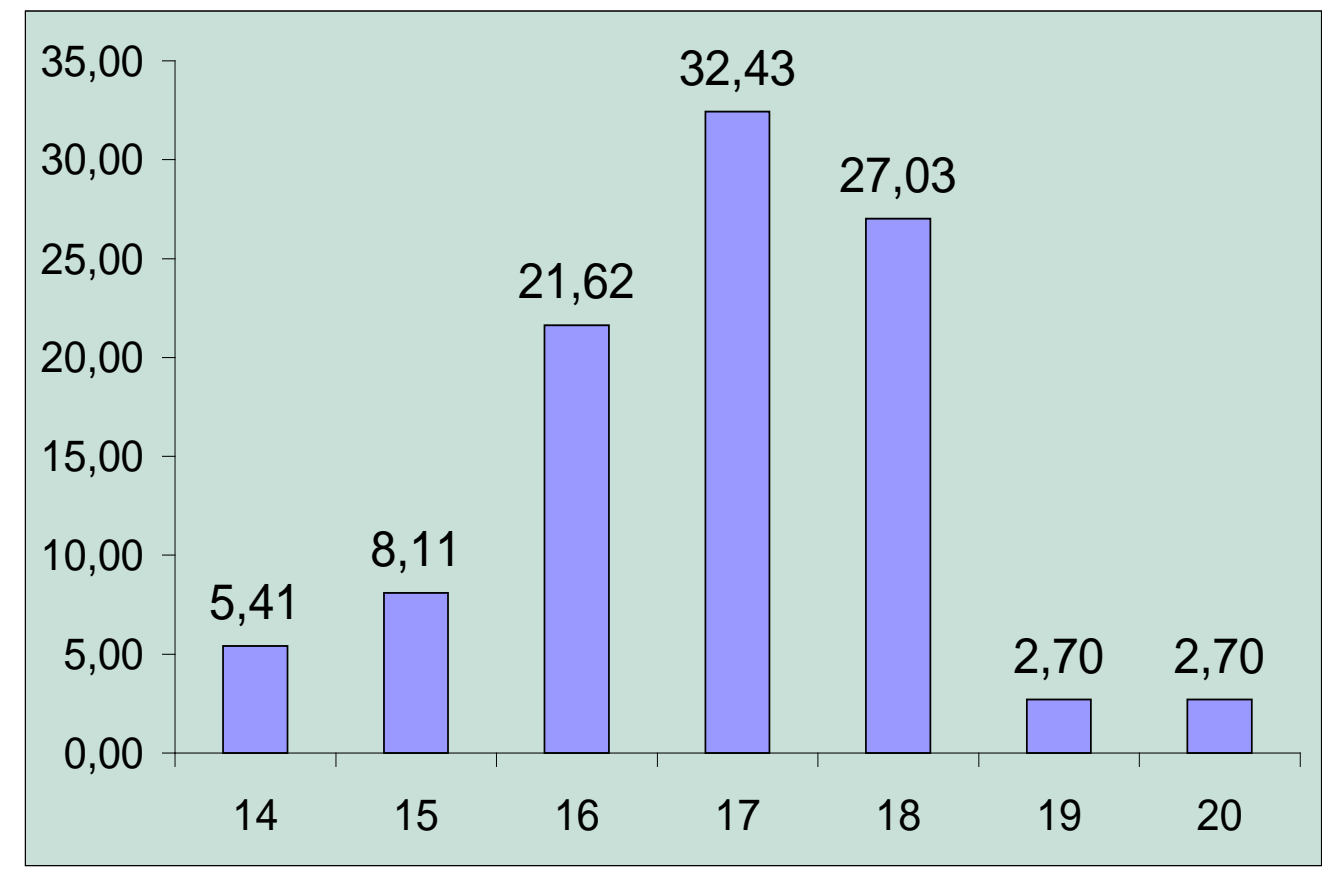

FONTE: Secretaria Municipal de Campo Largo

Pesquisas realizadas no Hospital São Paulo (SP) com adolescentes que eram atendidas no pré-natal entre 1996 e 1998 constataram que 38,5\% tinham menos de 16 anos e 61,5\% entre 17 e 19 anos. Em Campo Largo, apesar de as adolescentes receberem informações sobre métodos anticoncepcionais durante o pré-natal e consulta puerperal, 27,02\% engravidaram pela segunda vez. 


\section{GRÁFICO 2 - GRAU DE ESCOLARIDADE DAS ADOLESCENTES GRÁVIDAS}

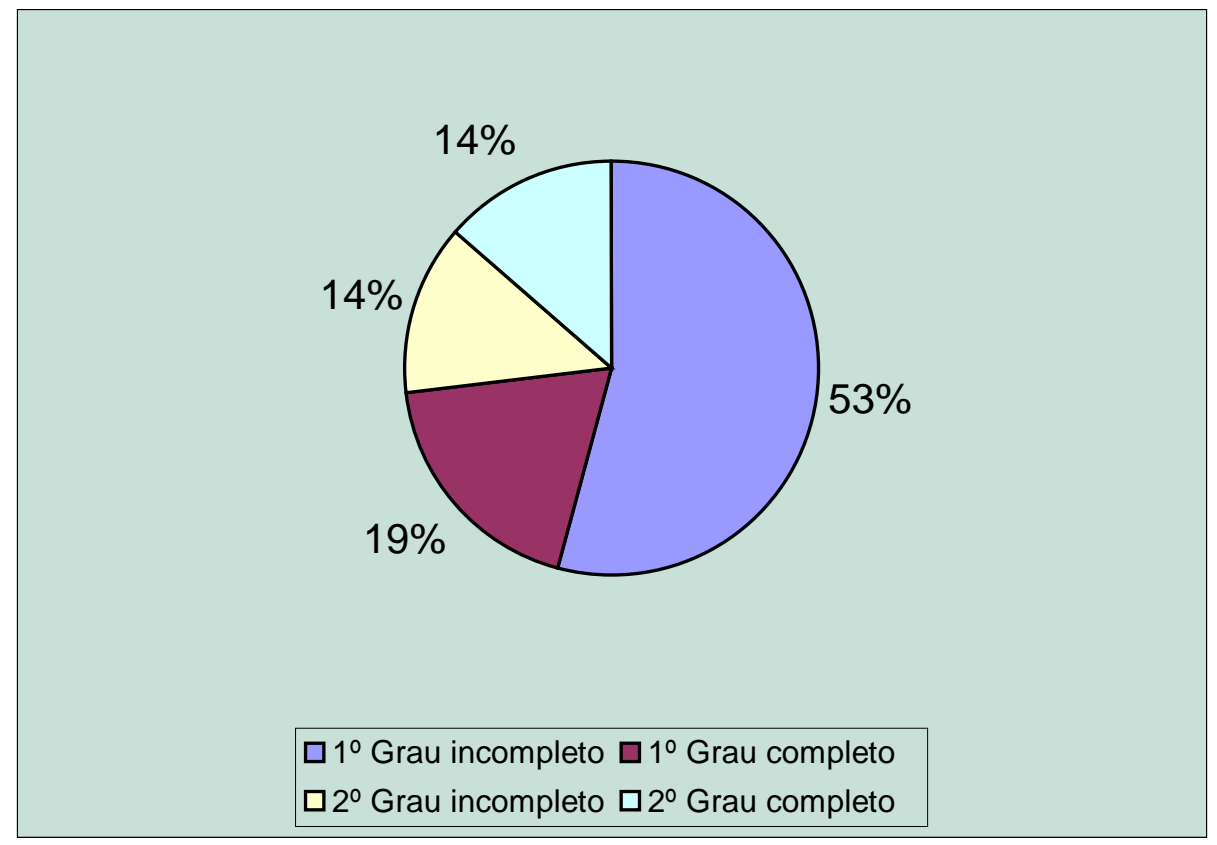

FONTE: Secretaria Municipal de Campo Largo

Sem dúvida a gravidez na adolescência é um dos principais fatores de evasão escolar entre os adolescentes. Como forte argumento disto é o gráfico acima, mostrando mais de 50\% das adolescentes sem sequer terem concluído o Ensino Fundamental.

GRÁFICO 3 - IDADE DE INÍCIO DA ATIVIDADE SEXUAL - 2002

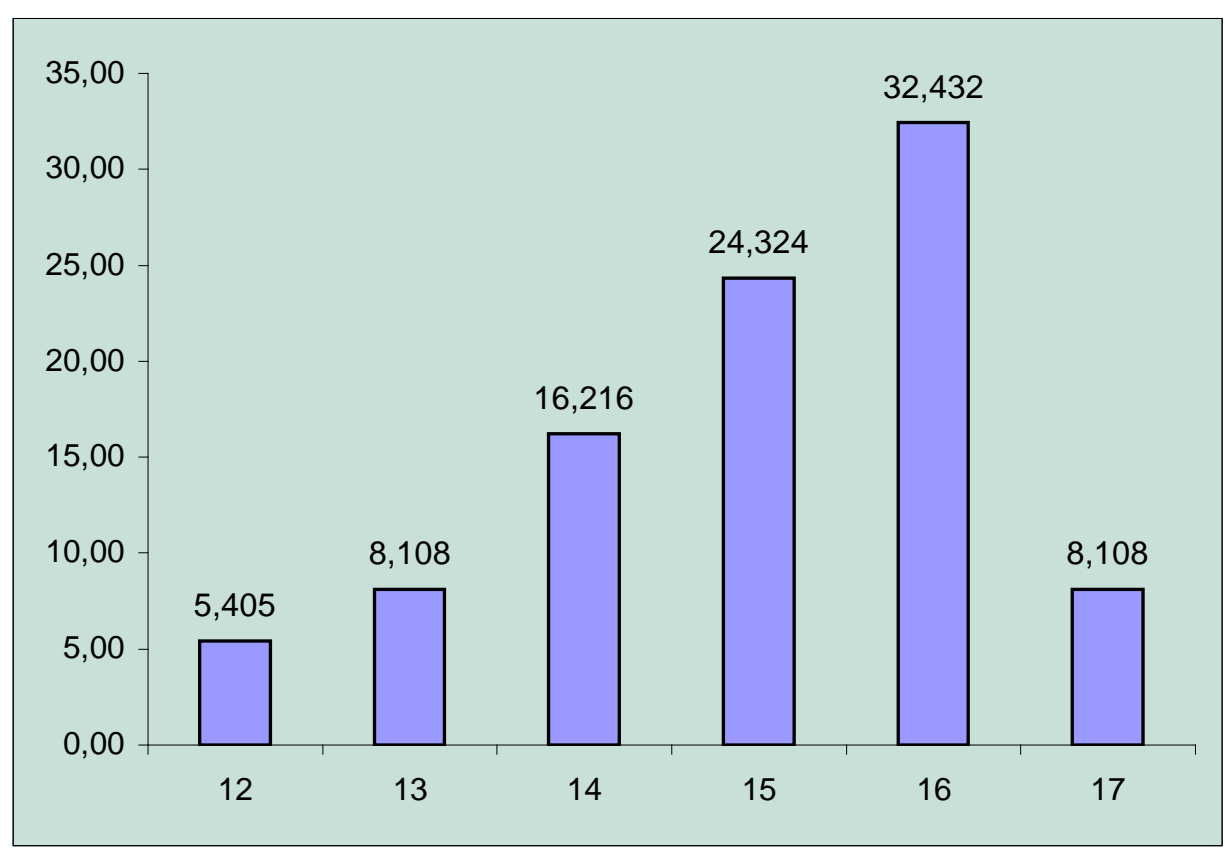

FONTE: Secretaria Municipal de Campo Largo 
D’ORO (1992) constatou que no município de São Carlos (SP), a idade média de início das relações sexuais é de 15.3, entre 200 adolescentes pesquisadas. Já no Hospital das Clínicas de São Paulo, a média é de 16.4 anos.

Em relação ao desejo de engravidar, observou-se que 51,35\% das adolescentes não queriam engravidar e 48,65\% a desejavam. Pesquisas em países em desenvolvimento mostram que $60 \%$ de casos de gravidez antes do 20 anos não são planejadas. Esse resultado pode ser causado pelo fato de as adolescentes iniciarem suas atividades sexuais precocemente, pela falta de informações, falta de métodos contraceptivos ou do uso incorreto dos mesmos (BALLONE, 2003).

No que diz respeito ao relacionamento com os familiares, 48\% responderam que têm ótimo relacionamento, $30 \%$ bom e $22 \%$ regular. O método contraceptivo mais utilizado foi a preservativo masculino (27.03\%); a maioria (42.24\%) delas não utilizavam nenhum método antes de engravidar.

\section{GRÁFICO 4 - PROJETO DE VIDA}

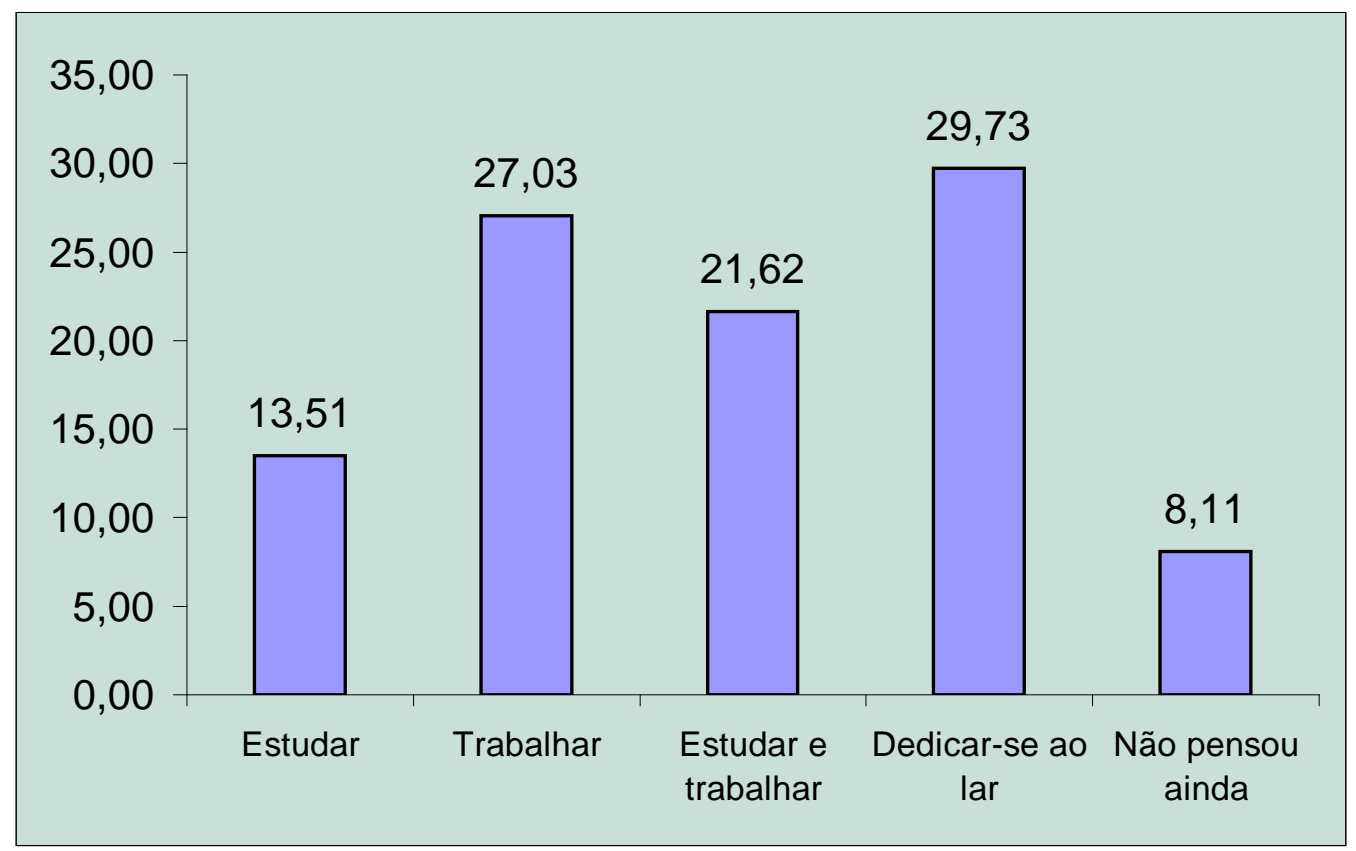

FONTE: Secretaria Municipal de Campo Largo

A gravidez na adolescência seria um grande obstáculo para os planos futuros das mesmas, embora muitas manifestem a sua vontade de prosseguir futuramente seus estudos, com certeza, isto se torna uma realidade bem mais distante e mais ainda quando consideradas as condições sócio-econômicas das adolescentes.

\section{MOTIVOS QUE INFLUENCIARAM NA OCORRÊNCIA DA GRAVIDEZ}

\subsection{ESTRUTURA FAMILIAR}

A família, em especial na figura dos pais, representa o centro ideal para discussão e esclarecimentos das dúvidas, angústias, tabus e preconceitos tão freqüentes em nossa sociedade. Cabe aos pais criarem um ambiente propício e acolhedor no lar onde, tanto, crianças quanto adolescentes possam ter a oportunidade de conversar abertamente questões que estarão 
diretamente relacionadas com o seu futuro, influenciando diretamente na decisão e rumo de vida de cada adolescente. O bom relacionamento dos pais com os filhos constitui um forte alicerce para a formação da sua personalidade.

\footnotetext{
"O meu relacionamento com o meu pai no começo foi difícil, a minha mãe não. A minha mãe assim que soube que eu estava grávida, morava no Augusta, não morava aqui ainda, liguei para ela, aí contei e ela me disse: Nossa! Você não acha que está muito nova! Mas ela aceitou numa boa, meu pai não. Nossa! Ele brigou tanto, para mim ele nunca falou nada, mas falava para minha mãe. Falava que ele não me queria mais aqui, não sei o que.........Ele ficou muito tempo sem falar comigo; daí ganhei, ele não veio ver a criança. Com 5 dias a minha mãe levou para ele ver a Maria Eduarda. Daí ele chorou, aí ficou tudo normal, mas ele não está conversando comigo. Não sei porque”. (Renilda, 20 anos).

"Moro com meu pai e minha irmã. Minha mãe é falecida há 9 anos. Meu pai não fala comigo desde que eu engravidei. Não sei se depois que eu ganhar ele vai fazer alguma coisa”. (Maria Rosilei, 18 anos).
}

A maioria dos psicólogos opina que todas as relações futuras de amor das filhas terão uma influência positiva ou negativa, dependendo do relacionamento ou percepção que elas tiveram dos seus respectivos pais. Assim, se o pai for um alcoólatra ou negligente, ela tentará substituir a imagem de pai por outra na sua vida. Se ele for carinhoso, ela buscará um noivo que o iguale. A imagem de si própria será positiva se o pai a considera como bonita e feminina. Mas, ela poderá apresentar sérios problemas de auto-estima até a vida adulta se o pai apresentar uma atitude contrária da citada anteriormente (DOBSON, 1991).

É claro que nenhuma dessas tendências é absoluta. As diferenças individuais sempre podem gerar exceções e contradições. Mas será difícil refutar esta afirmação: um bom pai deixará seu selo na sua filha pelo resto da sua vida.

\subsection{FATORES EDUCACIONAIS E PROJETO DE VIDA}

É durante a adolescência que o ser humano planeja o seu futuro profissional, constrói seus "sonhos" e cria meios para fazer com que isto seja uma realidade tangível. Quem eu sou? $\mathrm{O}$ que quero ser? Casamento? Quantos filhos eu terei? Quero ser um médico, comerciante, advogado, enfermeiro, gráfico ou ter meu próprio negócio? Morarei em apartamento ou numa casa de uma pequena cidade do interior ou de outra maior?

\footnotetext{
“Estudei até a sétima série, parei o ano passado. Estava trabalhando com auxiliar de limpeza, isso faz quatro meses, meu primeiro emprego. Gostaria de ser advogada ou engenheira, acho que meu filho não vai atrapalhar em nada, eu vou continuar estudando”. (Joice, 18 anos).

“Terminei o segundo grau completo no ano de 2000. Trabalhei até fevereiro de 2001 como auxiliar de cabeleireiro. Gostaria de fazer algo para ter contato com o público, por mim faria duas ou três faculdades......Após ter uma boa rentabilidade conseguirei estudar, porque trabalharia de dia e estudaria a noite, né? Daí sim, só que tenho que ganhar um salário mais ou menos para poder fazer uma faculdade”. (Vanussa, 18 anos).

"Estudei até a quarta série, parei o ano passado. Até o ano passado trabalhei de empregada. Gostaria de ser professora, acho que ainda vai dar. Vou criar meu filho e depois vou estudar”. (Izabel, 18 anos)”.
}

Segundo DONAS (1991) este “sonho” estará influenciado pelo meio externo e pelo próprio esforço do adolescente para que isto possa ser uma realidade.

A maternidade precoce dificulta o desenvolvimento educacional e social, assim como também a sua capacidade de utilizar todo o seu potencial. Isto acarreta numa taxa maior de evasão escolar, desajustes familiares e dificuldade de inserção no mercado de trabalho.

Das doze adolescentes entrevistadas, apenas uma está estudando, sete delas pretendem estudar e seis vêem essa possibilidade distante pelas necessidades do dia-a-dia que falam ainda 
mais alto, como expressa pela Maria Rosilei (18 anos) quando indagada sobre a pretensão de continuar estudando após a gravidez:

"Ah, eu tento mas não vai ter como; porque tenho que trabalhar também. Meu pai está doente, ele perdeu o emprego, só tem uma irmã que está trabalhando. Eu tenho que voltar a trabalhar, por isso acho que não vai dar para estudar”.

\section{SEXUALIDADE NA ADOLESCÊNCIA}

\subsection{IDADE DA MENARCA}

Estudos demonstram que a idade da menarca vem diminuindo cerca de 4 meses a cada década, encontrando-se, atualmente na faixa entre 12.5 e 13 anos. Isto serviria para um "despertar" mais cedo para sua sexualidade e conseqüentemente a possibilidade de experimentar a gravidez. Entre as entrevistadas tivemos várias reações e experiências entre as quais ressaltamos:

\footnotetext{
"Minha primeira menstruação veio com 9 anos. A primeira vez foi...Nossa! Pensei que estava morrendo, não sabia nada e nem estava esperando. Acho que não teve nada a ver com minha primeira relação (15 anos) (Rosemara, 16 anos)".

"A minha menstruação veio com 17 anos. Ah, sei lá, foi inexplicável, né? Fiquei meio assim com um pouco de medo, depois passou, porque tudo mundo falava para mim como que era. "Não esperava mesmo com 17 anos. Eu ia no médico para saber se tinha algum problema, que não era normal. Fiz uma ecografia, deu tudo normal. Daí estava com 17 e estava tudo normal. Minha primeira relação foi uns meses depois, acho que não influenciou, para mim aconteceu porque tinha que acontecer". (Maria Rosilei, 18 anos).
}

Apontar a menarca como único fator determinante ou tentar estimar qual a porcentagem de contribuição na adolescente frente à decisão da sua primeira experiência sexual ainda fica difícil de determiná-la com exatidão, porém também não podemos negar que a menarca exerce certa influência na "fantasia sexual” de cada adolescente e maturidade sexual.

\subsection{INICIAÇÃO SEXUAL}

A livre escolha de cada individuo, é um direito garantido por lei a todo ser humano, principalmente num país democrático como o Brasil. Quando uma experiência acontece contra a própria vontade deixa uma marca muito grande, e em especial, quando se fala da primeira relação sexual isto pode ser “chocante”, como segue o relato:

"Minha primeira relação foi com 10 anos. Não posso dizer o que me influenciou porque foi uma coisa muito ruim, foi um estupro. Senti uma coisa muito ruim. Fizemos queixa na polícia, mas eles não fizeram nada. Depois disso, a minha primeira relação que eu quis foi com 11 anos” (Janaína, 15 anos).

Nas demais que foram entrevistadas e que se iniciaram sexualmente falando por livre vontade, os sentimentos que a primeira relação sexual causou foram das mais diversas:

"Minha primeira relação foi com 15 anos. Tive curiosidade por experimentar, é que a minha mãe não conversava, tinha um monte de filhos, por essas coisas acho que foi curiosidade. Me senti culpada, porque era muito nova, eu acho". (Simone, 17 anos).

"Iniciei com 12 anos, tive 4 parceiros, me senti influenciada pela convivência que tinha com rapazes. Ah, não sei.... Não gostei, foi uma nova experiência na minha vida”. (Joice, 18 anos).

"Minha primeira vez foi com 17 anos e aconteceu quando comecei a namorar, sei lá, aconteceu.... para mim era meio desconhecido”. (Vanilda, 18 anos).

“Comecei com 13 anos, foi bom, não planejei nada mas já estava namorando”. (Beatriz, 18 anos). 
Segundo dados da pesquisa domiciliar (1989) pela fundação Pathfinder, realizada em cinco capitais brasileiras (Salvador, Rio de janeiro, São Paulo, Recife e Curitiba), a idade média da primeira relação dos jovens entrevistados foi de 16.9 para as mulheres e 15 anos para os homens, num total de 9066 jovens entre 15 e 24 anos. Esta mudança comportamental sexual tem como principal conseqüência a gravidez na adolescência. Outros fatores mencionados pelas adolescentes entrevistadas são a influência das amizades, conversa em roda de amigos, distanciamento entre pais e filhas, curiosidade e namoro.

\subsection{USO DE MÉTODOS ANTICONCEPCIONAIS (M.A.C.)}

$\mathrm{O}$ acesso aos M.A.C. para uso de forma regular é fundamental em se tratando de planejamento familiar, seja pelo barateamento dos mesmos ou disponibilizando-os nas Unidades de Saúdes Básicas.

Quando se fala em Saúde Reprodutiva, todo casal tem o direito de se reproduzir e ter a liberdade para decidir quando e com que freqüência irá fazê-lo. Isto implica que cada indivíduo, homem e mulher, tem o direito à informação e ao acesso aos métodos de planejamento familiar da sua escolha, que sejam, ao mesmo tempo, seguros, eficazes, aceitáveis e de baixo custo. Da mesma forma, os direitos reprodutivos se fundamentam no reconhecimento do direito básico de todo casal de decidir livremente e com responsabilidade sobre o número de filhos que deseja ter.

Assim, a informação e serviço de planejamento familiar são quesitos fundamentais para a obtenção e realização dos direitos reprodutivos e da saúde reprodutiva.

\footnotetext{
"Conheço a pílula, injeção e DIU, sei usar mais ou menos, quem me falou primeiro foi minha irmã, da primeira gravidez parei de usar (pílula) porque me dava azia e da segunda não usei nada”. (Simone, 17 anos).

"A gente sabe da pílula, injeção, DIU e camisinha. Só sei usar a injeção porque estou usando agora e o médico me ensinou. O posto sempre me dá". (Rosemara, 16 anos).

"Só sei da pílula, eu sei usar porque meu marido me falou". (Beatriz, 17 anos).
}

Os depoimentos acima revelam o escasso conhecimento sobre M.A.C, com informações vindas de fontes, muitas vezes, pouco seguras e mesmo aquelas recebidas de profissionais da área da saúde nem sempre completas ou atualizadas.

Isto nos faz refletir seriamente sobre a urgência na organização do sistema de saúde, disponibilidade dos M.A.C. nas Unidades de Saúde Básicas e na adequada capacitação dos profissionais da área da saúde (médicos, enfermeiros, psicólogos e auxiliares de enfermagem).

\section{A GRAVIDEZ NA ADOLESCÊNCIA: FANTASIA VERSUS REALIDADE}

\subsection{ACEITAÇÃO DA GRAVIDEZ}

Todo ser humano experimenta transformações no decorrer da vida, isto independente da idade: criança, jovem, adulto ou velho; cada um com suas particularidades. Porém, existem épocas da vida em que essas modificações ocorrem numa intensidade maior, tanto física quanto mentalmente, e entre elas certamente a gravidez ganha uma relevância toda especial.

\footnotetext{
“Não queria engravidar porque já é difícil criar um, imagina dois, né?”. (Janaína, 15 anos).

“Eu queria engravidar da primeira e da segunda vez”. (Beatriz, 17 anos).

“Minha gravidez foi planejada, eu queria”. (Renilda, 20 anos).
} 
"Não queria engravidar porque não tinha responsabilidade nem emprego para me manter, ao mesmo tempo que fico feliz, penso que não vou poder mais sair com as minhas amigas à noite nem estudar no colégio". (Andréia, 16 anos).

Ao engravidar, a jovem tem de enfrentar, paralelamente, tanto os processos de transformação da adolescência como os da gestação. Isto representa uma sobrecarga física e psíquica muito grande que para ser bem suportada necessitaria apoiar-se num desejo muito firme de tornar-se mãe. Porém, não é isto o que geralmente acontece. As adolescentes ficam assustadas e angustiadas diante da realidade da gravidez, merecendo assim, uma atenção toda especial por parte da equipe de atenção primária, na Unidade de Saúde Básica. A descoberta da gravidez indesejada, associada ao relacionamento deteriorado com os pais, faz com que as adolescentes grávidas iniciem o pré-natal tardiamente, agregando mais um fator complicador à difícil situação já existente.

Embora não tenha sido citado pelas pacientes, a sensação de plena segurança e desejo de autonomia, típicos da adolescência, influenciam os comportamentos de risco, como ter relações sexuais sem proteção, com o pensamento que "isso nunca aconteceria comigo". A expectativa de conhecer algo novo, viver momentos de prazer, impedem a avaliação dos riscos seja fazendo sexo ou pegando sem permissão a chave do carro do pai, desprezando as conseqüências de suas decisões. Ao deparar-se com a realidade, a sensação é de decepção e confusão entre o sonho e a vivência cotidiana.

"É difícil de explicar, em certo ponto eu queria, achava que ia melhorar meu relacionamento, tipo querer eu não queria, eu queria para tentar melhorar, mas daí não melhorou nada, piorou”. (Izabel, 18 anos).

A idéia de "melhorar o relacionamento" ou de "segurar o namorado" através de um filho se apresenta mais como uma tentativa fantasiosa por parte da adolescente do que como um método efetivo propriamente dito, acarretando uma surpresa não muito agradável nos rapazes que não amadureceram previamente a idéia de se tornarem pais.

\subsection{PERCEPÇÃO DE RISCO PARA A SAUDE}

Apesar de as adolescentes possuírem piores condições biológicas para a gravidez, o maior índice de complicações perinatais nessas pacientes se deve mais a uma interação biossocioeconômica, sendo que a assistência pré-natal adequada pode reduzir essas complicações a níveis próximos aos de uma paciente não adolescente.

\footnotetext{
“Se não estivesse fazendo pré-natal sim, mas como sou nova acho que não”. (Andréia, 16 anos).

"Acho que minha gravidez é um risco porque tenho medo que nasça antes da hora, não cresce direito o braço, complicações no parto ou algum problema no útero”. (Andréia, 16 anos).

"Penso que a minha gravidez é de risco, não sei porque, nunca ouvi falar de que é um risco". (Ana Paula, 17 anos)

“Eu acho que não tem problema, é só se cuidar, né?” (Simone, 17 anos).
}

Segundo VITIELLO (199?), quando comparadas as adolescentes grávidas com as não adolescentes, há maior incidência de: níveis pressóricos elevados, D.S.T. (gonorréia e sífilis), trabalho de parto prematuro e distócia funcional, principalmente pelo temor à dor do parto. Todos esses eventos podem sem dúvidas ser prevenidos com uma adequada assistência prénatal. 
Os serviços multidisciplinares voltados para o cuidado apenas das adolescentes têm melhores resultados pelo recrutamento precoce do pré-natal e obterem assim uma maior adesão ao acompanhamento, sendo ideal o envolvimento do parceiro, ou familiares neste processo.

\subsection{PERCEPÇÃO DE MUDANÇA DE VIDA}

A impulsividade, característica desta faixa etária, leva à relação sexual desprotegida e finalmente à gravidez, demonstrando que as adolescentes não têm a capacidade de associar uma ação no presente com a sua conseqüência no futuro.

"Antes eu saía, tinha liberdade, não precisava cuidar de ninguém, agora vou precisar cuidar do bebê, tem bastante coisa". (Ana Paula, 17 anos)

"Mudou a minha maneira de pensar, não em mim, penso no crescimento deles". (Simone, 17 anos).

"O que mudou comigo foram as pessoas, meu pai mudou comigo". (Maria Rosilei, 18 anos).

"Acho que agora sou mais forte em relação aos problemas". (Vanusa, 18 anos).

Quando indagadas sobre o que mudou após a gravidez, as mudanças apontadas pelas adolescentes geralmente giram em torno da "perca da sua liberdade social", relacionamentos familiares deteriorados (principalmente com o pai), olhar desconfiado dos vizinhos e uma forte afirmação de ganho de experiência e maturidade decorrente desta experiência.

\section{A ATUAÇÃO DO SERVIÇO DE SAUDE}

\subsection{AVALIAÇÃO CRÍTICA SÉRIA}

A ausência de serviços de saúde, com programas específicos para atender a demanda dos adolescentes fazem com que eles procurem obter informações em fontes nem sempre corretas, tais como nas farmácias, roda de amigos e familiares.

Há uma grande necessidade de que as Unidades de Saúde Básicas tenham profissionais treinados, prontos para orientação, prevenção, acolhimento e esclarecimento de dúvidas dos adolescentes e quando necessário, da adolescente grávida.

“Nunca ninguém do Posto me orientou, algumas vezes o Posto tinha pílulas”. (Ana Paula, 17 anos).

Todos os autores são unânimes em dizer que uma assistência pré-natal inadequada é o ponto de partida para as mais freqüentes complicações clínicas e obstétricas.

\subsection{AVALIAÇÃO DO ATENDIMENTO ADEQUADO}

A precariedade dos serviços de saúde pode ser apontada como fator relevante em se tratando de saúde pública, fornecimento de métodos anticoncepcionais e principalmente na adequada informação para os adolescentes. Informações que “capacitem” os adolescentes a tomarem suas próprias decisões sabendo que existem maneiras de se proteger e quais as conseqüências de uma eventual gravidez durante esse período.

"Não recebi orientação nenhuma. No postinho tem às vezes funcionários que não exercem muito bem a sua função de orientador”. (Renilda, 20 anos).

Orientar quer dizer guiar, encaminhar ou dirigir. O sistema impõe aos funcionários da Unidade de Saúde atender a livre demanda, obrigando muitas vezes a atender um número grande de pacientes que certamente irá comprometer seriamente a qualidade do atendimento. Isto associado a um investimento quase nulo por parte das Secretarias de Saúde no aperfeiçoamento dos profissionais (médico, enfermeiro, auxiliar de enfermagem, psicólogo, 
dentistas, assistente social, terapeuta ocupacional) faz com que a função de "educador em saúde" que estes deveriam cumprir, esteja muito longe de ser uma realidade nas Unidades que os adolescentes freqüentam.

\section{CONCLUSÃO}

Até certo tempo, a iniciação sexual do rapaz era realizada tradicionalmente com prostitutas, enquanto que as moças costumeiramente tinham a sua experiência sexual no casamento ou quase no final do noivado. A revolução sexual trouxe uma maior liberdade de expressão e de vida, principalmente, entre os jovens e os adolescentes.

O “ficar", expressão comum entre os adolescentes, dá a idéia de algo sem compromisso que vai desde a simples companhia física do parceiro até a relação sexual propriamente dita. Isto é tido como um processo "normal” de maturação psicossexual por muitos psicoterapeutas, acarretando muitas vezes, quando impensada e despreparada, numa gravidez ou numa D.S.T. (doença sexualmente transmissível). Partindo do princípio de que quando nos referimos à maturação falamos de "desenvolvimento" ou "aperfeiçoamento" surge uma contradição no que se refere ao processo da sexualidade, quando se aborda a relação sexual como "experiência normal” de amadurecimento dos adolescentes, se os adolescentes não estão amadurecidos para enfrentar as possíveis conseqüências desta experiência.

Os laços familiares enfraquecidos, desestruturados e pouco acolhedores representam um fator causal fundamental nas adolescentes grávidas, tendo duas grandes conseqüências, a curto e longo prazo a gravidez e a repetição dos mesmos problemas, já vivenciados pela adolescente hoje, transportando-se para o seu futuro lar, fazendo disto uma espécie de "ciclo repetitivo".

O projeto de vida da adolescente fica extremamente comprometido com a gravidez precoce, tornando bem distante a possibilidade de logros e sucessos que possam melhorar as suas condições sócio-econômicas e a ofertar aos seus filhos um ambiente bem melhor para poder criá-los.

A menarca possui uma influência, ainda não muito bem definida e sustentada por muitos autores, mesmo que no presente estudo não tenha sido referida como tal pelas adolescentes.

A iniciação sexual por influência, curiosidade ou "porque tinha que acontecer" demonstra ainda uma atitude impensada, sem noção das possíveis conseqüências decorrentes desta decisão.

Há necessidade dos profissionais da área da saúde e gestores, pensarem em métodos pedagógicos para oferecer aos adolescentes informações corretas e completas sobre os M.A.C.s com objetivo de diminuirmos os casos de gravidez por desconhecimento de anticoncepção; e, não só informando, mas também provendo de M.A.C. nas Unidades de Saúde Básicas.

Os depoimentos das entrevistadas demonstram uma alternância entre as que desejavam, e as que não desejavam a gravidez. Mesmo naquelas que se declararam a favor da sua gravidez, pelo contexto de vida e da entrevista, notamos que as mesmas não estavam aptas para esta experiência de vida.

As adolescentes não percebem a sua gravidez como um risco, porque elas estão se deparando com esta realidade inesperada de forma abrupta, e, a maioria delas sem sequer ter em mente se este evento nas suas vidas representa ou não algum risco para sua saúde e a do futuro filho.

As mudanças apontadas por elas demonstram a percepção de uma maior privação social, impedindo-as de realizar suas atividades principalmente de finais de semana. Outras apontaram uma mudança no que se refere à forma de encarar os problemas, fazendo hoje delas pessoas mais fortes e com uma visão diferente para encarar os problemas da vida. 
O sistema de saúde pode dar uma grande contribuição para influir neste tipo de evento. Muito interessante seria, que as escolas de medicina adotassem nos seus currículos escolares a organização do sistema de saúde, importância da atenção e capacitação do médico a situações especiais como a adolescente grávida e a conscientização do atendimento qualificado e para prevenção das possíveis complicações.

\section{REFERÊNCIAS}

BALLONE,G.J. Gravidez na Adolescência. In: PsiqWeb:

http://sites.uol.com.br;gballone/infantil/adoles3.html>revisto em 2003.

CALAZANS G. Cultura Adolescente e Saúde: Perspectivas para a Investigação. In: Oliveira M.O. CULTURA, ADOLESCÊNCIA E SAÚDE: ARGENTINA, BRASIL E MEXICO. Campinas, 2000. p. $44-97$.

D’ORO, A.C.D’A. Gravidez na adolescência:estudo de adolescentes grávidas em serviços de saúde da cidade de São Carlos, Estado de São Paulo. São Paulo, 1992 [Dissertação de Mestrado - Faculdade de Saúde Pública da USP].

DOBSON, J. Tener hijos no es para cobardes. Florida, Editora Vida, 1991.

DONAS, S. Marco epidemiologico conceptual de la salud integral del adolescente. In:

Cadernos Juventude, Saúde e Desenvolvimento. Brasília, v.I, ago. 1999.

LAO T.T., HO LF. The obstetric implications of teenage pregnancy. Hum Reprod 1997; 12:2303-5.

LESSER J, Escoto-Lloyd S. Health-related problems in vulnerable population: pregnant teens and adolescent mothers. Nurs Clin North Am 1999;14:289-99.

\section{APÊNDICE 1 - ENTREVISTA}

\section{IDENTIFICAÇÃO}

Idade.

Nível de instrução: até quando você estudou? Até que série você estudou?

Emprego.

2 FAMÍLIA

Membros da família: quem faz parte da sua família? Qual o grau de parentesco?

Como é o relacionamento como os seus pais?

Com qual (is) membro (s) da família compartilha os seus problemas, preocupações ou dúvidas?

Moradia: mora com o parceiro, familiares, etc. com quem você mora?

\section{MENARCA}

Com que idade foi a primeira menstruação?

Como você se sentiu em relação à menarca?

Recebeu orientação/apoio da família? 
4 INICIAÇÃO SEXUAL

Com que idade foi a sua primeira experiência sexual?

Quais foram os fatores que influenciaram?

$\mathrm{O}$ que representou a sua primeira relação?

Quais os sentimentos? Como a sua vida se modificou após iniciar vida sexual?

As primeiras informações foram obtidas a través de.....

A menarca influenciou na decisão da primeira relação sexual?

5 M.A.C.

Quais os métodos que conhece?

Sabe como utilizá-lo?

Quem a orientou?

Foi fornecido na U.S. ou adquirido na farmácia?

Onde você conseguiu informações sobre o MAC?

Estava usando algum M.A.C. quando engravidou?

6 GRAVIDEZ

Paridade

Desejava engravidar?

Que sentimentos a gravidez trouxe a você?

O que mudou em você após a gestação?

Pensa que a sua gravidez possa representar algum risco médico?

7 PROJETO DE VIDA

Gostaria de ser.......

Você vai continuar estudando?

8 UNIDADE DE SAÚDE

Quais as orientações recebidas de profissionais da área de saúde?

A U.S. forneceu algum MAC?

Como é ou foi o seu Pré-Natal em relação aos diversos profissionais: médico, enfermeira, auxiliares de enfermagem e recepcionista? 